\title{
Comparative Evaluation of the Effect of Chlorhexidine Gluconate, Raw Propolis and Hydrogen Peroxide on Dental Plaque and Gingival Inflammation
}

\author{
Dr. Surbhi Porwal, ${ }^{1}$ Dr. Aditi Mathur, ${ }^{1}$ Dr. Neema Shetty, ${ }^{1}$ \\ Dr. Balaji Manohar, ${ }^{1}$ Dr. Barkha Makhijani, ${ }^{1}$ Dr. Rohit Mundra ${ }^{2}$ \\ ${ }^{1}$ Department of Periodontics, Pacific Dental College and Research Centre, Udaipur, India; \\ ${ }^{2}$ Department of Prosthodontics, Pacific Dental College and Research Centre, Udaipur, India.
}

\begin{abstract}
Background: Plaque is the soft deposit that forms the biofilm consisting of microorganisms adhering to the tooth surface and is proved beyond doubt to be the initiator of gingival and periodontal disease. Plaque control is the mainstay in periodontal disease.

Aim: To compare the effect of $0.2 \%$ chlorhexidine gluconate, raw propolis and $3 \%$ hydrogen peroxide mouthwash on dental plaque and gingival inflammation.

Materials and Methods: Thirty subjects in the age group of 20-40 years were enrolledin the study. Plaque index and Modified Gingival Index were recorded at baseline and oral prophylaxis was performed. Subjects were then randomly divided into three groups $(\mathrm{n}=10)$ and were asked to rinse with $10 \mathrm{ml}$ mouthwash twice daily for 15 days. Group I received $0.2 \%$ chlorhexidine gluconate mouth wash, Group II raw propolis diluted with distilled water (1:1), and Group III 3\% hydrogen peroxide (1:1) mouthwash. Subjects were recalled on 7 day and 28 day for reevaluation and recording plaque index and modified gingival index. Statistical analysis was done to evaluate the efficacy of all the three mouthwashes.

Results: The results showed that all the three mouthwashes were effective in reducing plaque and gingival inflammation. Chlorhexidine gluconate $0.2 \%$ showed to be the most effective in reduction of dental plaque. Propolis was observed to be the most effective in reducing gingival inflammation over a period of 28 days.

Conclusion: Propolis can be effectively used as a mouthwash without any potential side effects as an alternative to chlorhexidine mouthwash in reducing gingival inflammation.

Keywords: Chlorhexidine gluconate; hydrogen peroxide; plaque; propolis.
\end{abstract}

\section{INTRODUCTION}

Periodontal diseases are infections of the structures surrounding the teeth. These include the gingiva, the cementum that covers the root, the periodontal ligament and the alveolar bone.

Approximately 95\% of the Indian population suffers from periodontal disease. In the earliest stage of periodontal disease, gingivitis, affects only gingiva. In more severe forms

\section{Correspondence:}

Dr. Surbhi Porwal

Department of Periodontics,

Pacific Dental College and Hospital, Udaipur, India.

email: drsurbhi.porwal@gmail.com

\section{Citation}

Porwal S, Mathur A, Shetty N, Manohar B, Makhijani B, Mundra R, Comparative Evaluation of the Effect of Chlorhexidine Gluconate, Raw Propolis and Hydrogen Peroxide on Dental Plaque and Gingival Inflammation. J Nepal Soc Perio Oral Implantol. 2018;2(1):14-9. of the disease, all of the supporting tissues are involved. The aetiology of dental disease mainly involves dental plaque. ${ }^{1}$

The role of dental plaque in the aetiology of dental diseases is well recognised. Thus, the treatment and prevention of gingivitis is a valuable goal in periodontal therapy. ${ }^{1}$ There is evidence which demonstrates that improving oral hygiene and gingival health has been associated with a decreasing incidence of periodontal disease. On the basis that plaqueinduced gingivitis always precedes the occurrence and recurrence of periodontitis, ${ }^{2}$ prevention of the periodontal disease including gingivitis and periodontitis has been defined as a multistage process, the mainstay of primary and secondary prevention of periodontal diseases is the control of supragingival plaque, which involves mechanical and chemical plaque control mechanical plaque control as first line option. ${ }^{1}$ Until now, mechanical cleansing is the most widely used method of supragingival plaque control and is effective in areas where access to plaque deposits is possible. ${ }^{3}$ 
Evidence exist that the degree of motivation and skill required with the oral hygiene products such as toothbrushes, dental floss, toothpicks, and interdental brushes may be beyond the ability of majority of the patients. There are also groups of individuals such as temporarily disabled individuals including non-ambulatory patients and handicapped people, for whom adequate oral hygiene is a problem. ${ }^{4}$ Therefore, an alternative method of plaque control would be desirable. Thus,chemical control may be relevant.

The purpose of the present study was to compare the effect of $0.2 \%$ chlorhexidine gluconate, raw propolis and 3\% hydrogen peroxide mouthwash in inhibiting the development of plaque and gingivitis.

The present study was undertaken to evaluate and compare the effects of to compare the effect of $0.2 \%$ chlorhexidine gluconate, raw propolis and $3 \%$ hydrogen peroxide mouthwash on dental plaque and gingival inflammation.

\section{MATERIALS AND METHODS}

In this clinical study, 30 subjects in the age group of 2040 years were enrolled from the out-patient Department of Periodontics. An informed consent from the subjects participating in this study was obtained before the commencement of this study and Ethical Clearance was obtained.

\section{Inclusion criteria:}

I. Systemically healthy subjects with chronic generalized gingivitis.

II. Modified Gingival Index of 3 (Lobene et al).

III. Plaque index of 4 (Turesky-Gilmore-Glickman modification of Quigley Hein Plaque index)

IV. No evidence of radiographic bone loss.

V. No clinical attachment loss.

\section{Exclusion criteria:}

I. Use of any systemic antibiotics \& anti-inflammatory drugs in the past 6 months.

II. Orthodontic treatment or bridge work that would interfere with evaluation.

III. Allergy to ingredients used in the study.

V. Pregnant or lactating females.

VI. Patient with poor compliance.

Group distribution- The subjects were randomly divided into three equal groups:

Group I ( $\mathrm{n}=10)$-Subjects using $0.2 \%$ chlorhexidine mouthwashdiluted with distilled water (1:1 ratio)

Group II ( $\mathrm{n}=10)$ - Subjects using raw propolis mouthwash diluted with distilled water (1:1 ratio)

Group III $(\mathrm{n}=10)$ - Subjects using 3\% Hydrogen Peroxide mouthwash diluted with distilled water (1:1 ratio).

Before allocating the subjects to the groups, they underwent thorough scaling and root planing.

\section{Parameters Recorded-}

I. Plaque Index (Turesky-Gilmore-Glickman modification of Quigley-Hein)

II. Modified Gingival Index (GI) (Lobene et al)

The clinical parameters were recorded at baseline, 7 and 28 days respectively.

The statistical analysis for inter and intra- group comparison was done using Student's paired and unpaired ' $t$ ' and oneway ANOVA (Analysis of Variance) tests. P value of $<0.05$ was considered statistically significant.

\section{RESULTS}

Plaque index (Turesky-Gilmore-Glickman modification of Quigley Hein Plaque index)and Modified Gingival Index (Lobene et al) (Table 1a, 1b, 2, 3) (Figure 1,2)

Table 1: Plaque Index (Turesky-Gilmore-Glickman modification of Quigley Hein) and Modified Gingival Index (Lobene et al).

\begin{tabular}{|c|c|c|c|c|c|c|c|c|}
\hline & \multicolumn{2}{|c|}{ Baseline } & \multicolumn{2}{|c|}{7 day } & \multicolumn{2}{|c|}{ 28day } & \multicolumn{2}{|c|}{$\%$ reduction from baseline to 28 days } \\
\hline & PI & MGI & PI & MGI & PI & MGI & PI & MGI \\
\hline \multicolumn{9}{|l|}{ Group I } \\
\hline Mean & 3.26 & 3.04 & 1.10 & 0.50 & 0.82 & 0.54 & \multirow{2}{*}{$74.84 \%$} & \multirow{2}{*}{$82.23 \%$} \\
\hline SD & 0.53 & 0.23 & 0.35 & 0.25 & 0.45 & 0.35 & & \\
\hline \multicolumn{9}{|l|}{ Group II } \\
\hline Mean & 3.34 & 3.16 & 1.62 & 0.75 & 0.94 & 0.28 & \multirow{2}{*}{$71.85 \%$} & \multirow{2}{*}{$91.13 \%$} \\
\hline SD & 0.25 & 0.34 & 0.68 & 0.38 & 0.57 & 0.25 & & \\
\hline \multicolumn{9}{|c|}{ Group III } \\
\hline Mean & 3.12 & 2.92 & 1.56 & 1.33 & 1.28 & 0.86 & \multirow{2}{*}{$58.97 \%$} & \multirow{2}{*}{$70.54 \%$} \\
\hline SD & 0.44 & 0.31 & 0.54 & 0.64 & 0.26 & 0.11 & & \\
\hline
\end{tabular}


Table 2: Plaque Index (Turesky-Gilmore-Glickman modification of Quigley Hein) and Modified Gingival Index (Lobene et al).

\begin{tabular}{|c|c|c|c|c|c|c|}
\hline & \multicolumn{2}{|c|}{ Baseline - 7 day } & \multicolumn{2}{|c|}{ Baseline - 28day } & \multicolumn{2}{|c|}{ 7day - 28day } \\
\hline & PI & MGI & PI & MGI & PI & MGI \\
\hline \multicolumn{7}{|l|}{ Group I } \\
\hline Mean Difference & 2.16 & 2.54 & 2.44 & 2.50 & 0.28 & 0.04 \\
\hline SD & 0.52 & 0.24 & 0.70 & 0.36 & 0.58 & 0.22 \\
\hline P Value & 0.001 & $<0.0001$ & 0.001 & $<0.0001$ & 0.341 & 0.738 \\
\hline \multicolumn{7}{|l|}{ Group II } \\
\hline Mean Difference & 1.72 & 2.41 & 2.40 & 2.88 & 0.68 & 0.46 \\
\hline SD & 0.48 & 0.34 & 0.41 & 0.32 & 0.43 & 0.21 \\
\hline P Value & 0.001 & $<0.0001$ & $<0.0001$ & $<0.0001$ & 0.025 & 0.008 \\
\hline \multicolumn{7}{|l|}{ Group III } \\
\hline Mean Difference & 1.56 & 1.59 & 1.84 & 2.06 & 0.28 & 0.47 \\
\hline SD & 0.80 & 0.77 & 0.52 & 0.28 & 0.50 & 0.60 \\
\hline P Value & 0.012 & 0.010 & 0.001 & $<0.0001$ & 0.276 & 0.155 \\
\hline
\end{tabular}

Table 3: Intergroup Comparison (P Values).

\begin{tabular}{|l|c|c|c|c|c|c|}
\hline & \multicolumn{2}{|c|}{ Baseline } & & \multicolumn{2}{c|}{7 day } & \multicolumn{2}{c|}{ Pday } \\
\cline { 2 - 7 } & PI & MGI & PI & MGI & PI \\
\hline Group I Vs Group II & 0.767 & 0.529 & 0.168 & 0.263 & 0.721 & 0.225 \\
\hline Group I Vs Group III & 0.660 & 0.508 & 0.146 & 0.028 & 0.083 & 0.082 \\
\hline Group II Vs Group III & 0.359 & 0.275 & 0.881 & 0.120 & 0.258 & 0.002 \\
\hline
\end{tabular}

Table 4: Analysis of Variance.

\begin{tabular}{|l|c|c|c|c|c|c|}
\hline & \multicolumn{2}{|c|}{ Baseline } & \multicolumn{2}{c|}{7 day } & \multicolumn{2}{c|}{ 28day } \\
\cline { 2 - 8 } & PI & MGI & PI & MGI & PI & MGI \\
\hline F value & 0.346 & 0.816 & 1.385 & 4.41 & 1.435 & 6.423 \\
\hline P value & 0.71 & 0.466 & 0.287 & 0.036 & 0.276 & 0.012 \\
\hline
\end{tabular}

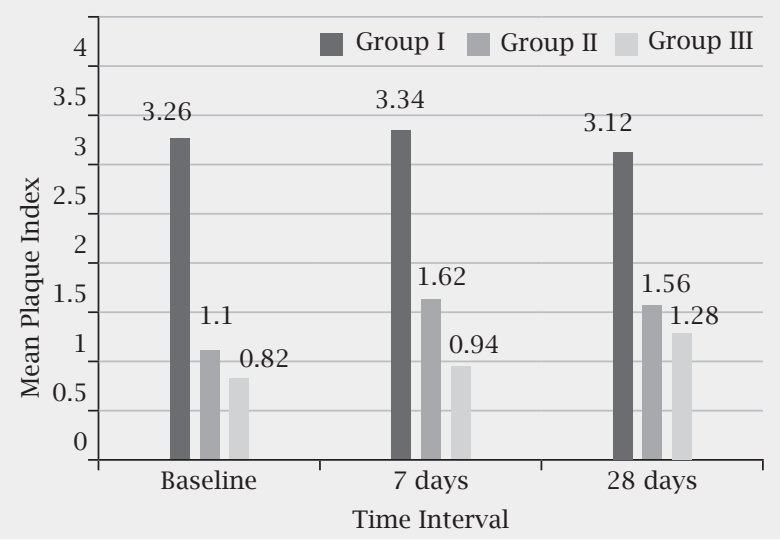

Figure 1: Plaque index.

At baseline no significant difference was observed in both the plaque index and modified gingival index in all the three groups $(\mathrm{p}>0.05)$.

When intra group comparison in Group I from baseline to 7 days and baseline to 28 days was done, it was observed that the plaque index and modified gingival index values reduced from $3.26 \pm 0.53$ to $1.10 \pm 0.35$ at 7 days to $0.82 \pm 0.45$ at the end of 28 days and from $3.04 \pm 0.23$ to $0.50 \pm 0.25$ at 7 days to $0.54 \pm 0.35$ at the end of 28 days respectively. The

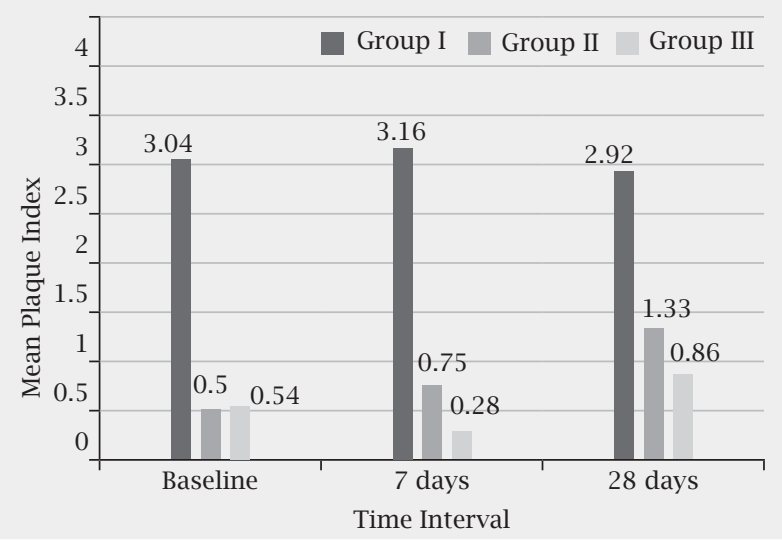

Figure 2: Modified gingival index.

overall percentage reduction in plaque score was $74.84 \%$ from baseline to 28 days and for the modified gingival index it was $82.23 \%$ from baseline to 28 days. When intra group comparison for Group I was done statistically significant difference was found from baseline to 7 days for plaque index ( $\mathrm{p}=0.001$ ) whereas; highly significant difference ( $p<0.0001$ ) was found for modified gingival index. When compared from baseline to 28 days statistically significant difference was found for plaque index $(\mathrm{p}=0.001)$ and $\mathrm{a}$ 
highly significant difference was found for modified gingival index ( $\mathrm{p}<0.0001$ ). However, when 7 to 28 day comparison was done no statistical difference was found for both plaque index and modified gingival index.

The intragroup comparison in Group II from baseline to 7 days and baseline to 28 days was done, it was observed that the plaque index and modified gingival index values reduced from $3.34 \pm 0.25$ to $1.62 \pm 0.68$ at 7 days to $0.94 \pm 0.57$ at the end of 28 days and from $3.16 \pm 0.34$ to $0.75 \pm 0.38$ at 7 days to $0.28 \pm 0.25$ at the end of 28 days respectively. The overall $\%$ age reduction in plaque index was $71.85 \%$ from baseline to 28 days and for modified gingival score was $91.13 \%$ from baseline to 28 days. When intra group comparison for Group II was done statistically significant difference was found from baseline to 7 days for plaque index $(\mathrm{p}=0.001)$ whereas; highly significant difference $(p<0.0001)$ was found for modified gingival index. When compared from baseline to 28 days was performed a highly significant difference was found for both plaque index and modified gingival index ( $\mathrm{p}$ $<0.0001)$. However; when 7 to 28 day comparison was done, a statistically non-significant difference was found for both plaque index $(\mathrm{p}=0.025)$ and for modified gingival index $(\mathrm{p}$ $=0.008)$.

In Group III intragroup comparison from baseline to 7 days, baseline to 28 days for plaque index and modified gingival index values reduced from $3.12 \pm 0.44$ to $1.56 \pm 0.54$ at 7 days to $0.1 .28 \pm 0.26$ at the end of 28 days and from $2.92 \pm 0.31$ to $1.33 \pm 0.63$ at 7 days to $0.86 \pm 0.11$ at the end of 28 days respectively. The overall \% age reduction in plaque score was $58.97 \%$ from baseline to 28 days and for modified gingival index was $70.54 \%$ from baseline to 28 days. When intra group comparison for Group III was done,a statistically significant difference was found from baseline to 7 days modified plaque index $(\mathrm{p}=0.012)$ and for modified gingival index ( $\mathrm{p}$ $=0.010)$. When compared from baseline to 28 days again a statistically significant difference was found for plaque index $(\mathrm{p}=0.001$ ) whereas; a highly significant difference was found for modified gingival index ( $\mathrm{p}<0.0001)$. However; when a 7 to 28 day comparison was done no statistical difference was found for both plaque index $(\mathrm{p}=0.276)$ and modified gingival index $(\mathrm{p}=0.155)$.

When comparison was done between Group I and Group II no statistically significant difference was found for both the groups at baseline, 7 days and at the end of 28 days. Between Group I and Group III, Group I was found with better results in reducing modified gingival index at 7 day. Comparing Group II and Group III, Group II was found to be better in the reduction of modified gingival index after 28 days.
The results showed that all the three mouthwashes were effective in reducing the plaque and inflammation. 0.2\% chlorhexidine gluconate being the most effective for reduction in dental plaque. Raw propoliswas observed to be the most effective in reducing gingival inflammation over a period of 7 days and 28 days.

The results of our study suggest that raw propolis has a plaque inhibitory effect which is statistically equal to chlorhexidine mouthwash and is more potent than chlorhexidine gluconate and 3\% hydrogen peroxide in reducing gingival inflammation.

\section{DISCUSSION}

Among the evaluated agents for chemical plaque control, chlorhexidine is the gold standard, as supported by a large body of evidence, produced since 1970. Chlorhexidine is a cationic bis-biguanide biocide with low mammalian toxicity and broad-spectrum antibacterialactivity, was first described in $1954 .^{7,8}$ The primary mechanism of action of this biocide is membrane disruption, causing concentration-dependent growth inhibition and cell death. ${ }^{9}$ Secondary interactions causing inhibition of proteolytic and glycosidic enzymes may also be significant. ${ }^{10}$ With respect to dental hygiene applications, the cationic nature of chlorhexidine enables it to bind to tooth surfaces and oral mucosa, reducing pellicle formation and increasing substantivity through controlled release of the agent. ${ }^{11}$ The efficacy of chlorhexidine in reducing oral bacterial viability ${ }^{12-14}$ strongly inhibiting plaque regrowth and preventing gingivitis ${ }^{15}$ has been demonstrated in many studies. ${ }^{16}$

Though chlorhexidine is considered as the best agent for plaque control and gingivitis, many patients find its initial bitter taste unpleasant and repeated use often produces stains and taste disturbances. Because of this, daily rinsing with chlorhexidine is not promoted. It would, however; be desirable to have the possibility to use chlorhexidine over an extended period of time. The absence of stain formation could improve patient compliance and reduce the time necessary to clean the dentition during recall.

Propolis was used by the Egyptian and Greek civilizations which recognized its healing qualities. Hippocrates, the founder of modern medicine, used it for healing sores and ulcers internally and externally. Propolis has been used in dentistry for various purposes and has a promising role in future medicine as well as in dentistry.

Murray et al. (1997) ${ }^{17}$ investigated the effectiveness of a propolis-containing mouth rinse in the inhibition of de novo plaque formation. Results showed chlorhexidine mouth rinse was significantly better than the others in plaque inhibition. The propolis-containing rinse was marginally better than the negative control, but this difference was not significant. However, the results of our study showed that both chlorhexidene and propolis are equally effective in reducing 
plaque but propolis is more effective in reducing gingival inflammation when compared with other mouthwashes.

Mundo et al, $2004^{18}$ stated that hydrogen peroxide has been shown to form in honey by the action of the enzyme glucose oxidase that produces gluconic acid and hydrogen peroxide from glucose.

Oxygenating agents have been employed for supragingival plaque control and in the treatment of acute ulcerative gingivitis without any harmful side effects on the tissues. ${ }^{19}$ 1.5\% Hydrogen peroxide has been shown to have a good stain removing capability both in vitro and in vivo. The use of Hydrogen peroxide as an adjunct to chlorhexidene has been found to be very effective in reducing plaque scores and in preventing the stain development. ${ }^{20}$ In the present study there was no significant difference in dental plaque reduction between propolis and chlorhexidine mouthwash. Similar results were observed by Nayak et $\mathrm{al}^{21}$ who analyzed the effect of Manuka honey and chlorhexidine mouthwash against plaque. However, Gupta $\mathrm{D}^{22}$ et al found significant difference between honey and chlorhexidine mouthwash when compared against plaque. In our study both $0.2 \%$ chlorhexidine and 3\% hydrogen peroxidewhen used alone can equally cause reduction in plaque. Whereas, Bhardwaj $\mathrm{VK}^{23}$ show that the therapeutic action of $0.2 \%$ chlorhexidine to inhibit supragingival plaque does not seem to be disturbed when it is used together with hydrogen peroxide solution.

Gusberti $^{24}$ showed the subjects rinsing with $0.12 \%$ chlorhexidine showed 95\% reduction in gingivitis incidence, $100 \%$ reduction in bleeding sites, and $80 \%$ reduction in plaque scores compared to the subjects rinsing with placebo. Conversely, the group using $1 \%$ hydrogen peroxide showed a marginal reduction in gingivitis incidence of $15 \%$ and a $28 \%$ reduction in bleeding sites compared to the placebo group, but no significant reduction in plaque scores. However our study showed no significant difference in plaque score among subjects using $0.2 \%$ chlorhexidine and $3 \%$ hydrogen peroxide. The group using $0.2 \%$ chlorhexidine showed greater reduction in gingival inflammation as compared to the group using 3\% hydrogen peroxide. Singh $\mathrm{N}^{25}$ reported that chlorhexidene rinse brought about significantly higher effect on preventing plaque accumulation than 10\% honey. Abbas et $\mathrm{al}^{26}$ Abdullah et $\mathrm{al}^{27}$ also showed similar results. However, greater reduction seen in the gingival bleeding scores rather than the plaque score in the honey group which was similar to our study.

Microbial resistance to propolishas never been reported which makes it a very promising topical antimicrobial agent against the infection of antibiotic resistant bacteria. Though many studies have evaluated effects of propolis on dental plaque reduction and periodontitis, in our knowledge this is the 1st study to compare effect on gingival inflammation using propolis, Chlorhexidine Gluconate and hydrogen peroxide. We found that there is a significant difference between propolis, Chlorhexidine and hydrogen peroxide suggesting propolis being more effective in reducing gingival inflammation.

\section{CONCLUSION}

Within the limits of the present study and on the basis of results obtained, it may be concluded that:

1. At baseline no significant difference was present for both modified plaque index and modified gingival index in all three groups

2. When intra group comparison was done for all the three group from baseline to 7 days, baseline to 28 days both Plaque index and Modified gingival index the values reduced.

3. When inter group comparison was done between Group I and Group II, no stastistically difference was found for both the groups at baseline, 7 days and 28 days

4. Propolis was found to be better in reducing Modified gingival index at 7 days when compared to chlorhexidine. Propolis was also seen to be better in Modified gingival index reduction after 28 days when compared to $3 \%$ hydrogen peroxide.

5. Chlorhexidine gluconate users the most effective for dental plaque reduction. Propoliswas observed to be the most effective in reducing gingival inflammation over a period of 7 days and 28 days.

6. The results of our study suggest that propolis has a plaque inhibitory effect which is statistically equal to $0.2 \%$ chlorhexidine mouthwash and is more potent than chlorhexidine gluconate and 3\% hydrogen peroxide in reducing gingival inflammation.

7. Use of propolis in the treatment of various diseases and ailments is well known from ancient times, but the use of propolis in oral disease is not much documented. Present study suggests that propolis can be effectively used in reduction of gingival inflammation without any potential side effect. 


\section{REFERENCES}

1. Jan AM, Verkade H, Timmerman MF, Van der Weijden FA. Comparison of two commercial chlorhexidine mouthwashes. J Periodontol. 2003;74:214-8.

2. Lindhe J, Karring T, Lang NP. Oxford: Blackwell Munksgaard; Clinical Periodontology and Implant Dentistry. 2003;4th edition:Chapter 7:198.

3. Francesso AG, Sampathkumar P, Beatrice E. Microbiological and clinical effects of chlorhexidine digluconate and hydrogen peroxide mouthrinse osn developing plaque and gingivitis. J Clin Periodontol. 1988;15:60-7.

4. Fischman SL. History of oral hygiene products. How far we have come in 6000 years? Periodontol 2000. 1997;15:7-14.

5. Turesky S, Gilmore ND, Glickman I. Reduced plaque formation by the chloromethyl analogue of vitamin C. J Periodontol. 1970;41(1):413.

6. Lobene RR, Mankodi SM, Ciancio SG, Lamm RA,Charles CH, Ross NM. Correlations among gingival indices. A methodology study. J Periodontol. 1989;60:159-62.

7. Denton GW. Chlorhexidin. InS.S. Block (ed.), Disinfection, sterilization and preservation, Lea and Febiger, Philadelphia, Pa. 1991;4:27489.

8. Davie GE, Francis J, Martin AR, Rose FL, Swain G. 1:6-Di 4-chlorophenyldiguanidohexane ("Hibitane"). Laboratory investigation of a new antibacterial agent of high potency. Br J Pharmacol. 1954;9:192-6.

9. Hugo WB, Longworth AR. The effect of chlorhexidine on the electrophoretic mobility, cytoplasmic constituents, dehydrogenase activity and cell walls of Escherichia coli and Staphylococcus aureus. J Pharm Pharmacol. 1966;18:569-78.

10. Hastings DC. Non-antibiotic plaque chemotherapy. In HN. Newman and M. Wilson. Dental plaque revisited: oral biofilms in health and disease. Bioline Press, Cardiff, United Kingdom. 2000;523-48.

11. Bonesvoll P, Lokken P, Rölla G, Paus PN. Retention of chlorhexidine in the human oral cavity after mouthrinses. Arch Oral Biol. 1974;19:1209-12.

12. Hase JC, Edwardsson S, Rundegren J, Attstrom R, Kelty E. Six-month use of 0.2\% delmopinol hydrochloride in comparison with 0.2\% chlorhexidine digluconate and placebo. II. Effect on plaqueandsalivarymicroflora. J Clin Periodontol. 1998;25:841-9.

13. Rosin M, Welk A, Kocher T, Majic-Todt A, Kramer A, Pitten FA. The effect of a polyhexamethylenebiguanide mouth rinse compared to an essential oil rinse and a chlorhexidine rinse on bacterial counts and 4-day plaque re-growth. J Clin Periodontol. 2002;29:392-9.

14. Muyzer G, Smalla K. Application of denaturing gradient gel electrophoresis (DGGE) and temperature gradient gel electrophoresis (TGGE) in microbial ecology. Antonie Leeuwenhoek. 1998;73:127-41.

15. Löe H, Schiött CR. The effect of mouthrinses and topical application of chlorhexidine on the development of dental plaque and gingivitis in man. J Peridontal Res. 1970;5:79-83.

16. Emilson CG. Potential efficacy of chlorhexidine against mutans streptococci and human dental caries. J Dent Res. 1994;73:682-91.

17. Murray MC, Worthington HV, Blinkhom AS. A study to investigate the effect of a propolis-containing mouthrinse on the inhibition of de novo plaque formation. J Clin Periodontol. 1997;24(11):796-8.

18. Mundo MA, Padilla-Zakour OI, Worobo RW. Growth inhibition of foodborne pathogens and food spoilage organisms by select raw honeys. Int J Food Microbiol. 2004;97:1-8.

19. Donna BL, Grundeman LJ, Steinfort J, Timmerman MF, van der Weijden GA. The inhibitory effect of combining chlorhexidine and hydrogen peroxide on 3 day plaque accumulation. J Clin Periodontol. 1998;25:879-83.

20. Grundeman LJ, Timmerman MF. Stain and plaque reduction by combining chlorhexidine and perborate. J Clin Periodontol. 2000;27:915 .

21. Nayak PA, Nayak UA, Mythili R. Effect of Manuka honey, chlorhexidine gluconate and xylitol on the clinical levels of dental plaque. Contemp Clin Dent. 2010;4:214-7.

22. Gupta D Bhaskar, DJ, Jain A, Agali C, Gupta V, Kumar R, Yadav P, Lavate AB, Chaturvedi M. Comparative evaluation of honey, chlorhexidine gluconate $(0.2 \%)$ and combination of xylitol and chlorhexidine mouthwash (0.2\%) on the clinical level of dental plaque: A 30 days randomized control trial. Clin Res. 2015;6(1):53-7.

23. Bhardwaj VK, Jhingta P, Bhardwaj A, Sharma D, Kumar N, Vaid S.Effect of hydrogen peroxide mouthwash as an adjunct to chlorhexidine on stains and plaque. J Indian Soc Periodontol 2013;17(4):449-53.

24. Gusberti FA, Sampathkumar P, Siegrist BE, Lang NP. Microbiological and clinical effects of chlorhexidine digluconate and hydrogen peroxide mouthrinses on developing plaque and gingivitis. J Clin Periodontol. 1988;15(1):60-7.

25. Singh N, Charde P, Bhongade ML. Comparative Evaluation between Honey and Chlorhexidine Gluconate on the Dental Plaque Levels and Gingival Health. Adv Dent Oral Health Res. 2016;1(5)

26. Abbas DK, Thrane P, Othman SJ. Effectiveness of veadent as plaque-inhibiting mouthwash. Scand J Dent Res. 1985;93(6):494-7.

27. Abdullah BA, Al-Talib RA, Al-Sultan FA. Comparative antiplaque activity of propolis extract and chlorhexidene in vitro. Al-Rafidain. Dent J. 2003; 3(1):7-12. 